\title{
Effects of Benzopyrene-7,8-Diol-9,10-Epoxide (BPDE) In Vitro and of Maternal Smoking In Vivo on Micronuclei Frequencies in Fetal Cord Blood
}

\author{
MARTA ZALACAIN, LUIS SIERRASESUMAGA, CARLOS LARRAÑAGA, AND ANA PATIÑO-GARCÍA \\ Department of Pediatrics [M.Z., L.S., A.P.-G.], University Clinic and University of Navarra, 31080 Pamplona, Spain; Department of \\ Gynecology and Obstetrics [C.L.], Virgen del Camino Hospital, 31008 Pamplona, Spain
}

\begin{abstract}
Up to $20 \%$ of pregnant women smoke and there is indirect evidence that certain tobacco-specific metabolites can cross the placental barrier and are genotoxic to the fetus. The presence of micronuclei results from chromosome damage and reflects the degree of underlying genetic instability. Fetal blood was obtained from the cord blood of 143 newborns (102 from nonsmoking mothers and 41 from mothers smoking $>10$ cigarettes/d during pregnancy). The micronucleus assay was performed following the guidelines established by the Human MicroNucleus project with modifications. To test the micronucleus assay, we evaluated the effect of a range of benzopyrene-7,8-diol-9,10-epoxide concentrations (from $3.125 \mathrm{nM}$ to $4 \mu \mathrm{M}$ ) on cord blood from nonsmoking mothers. This validation showed that the number of micronuclei and apoptotic cells increased with benzopyrene-7,8-diol-9,10-epoxide dose $(p<0.0001$ and $p=$ 0.001 , respectively); the minimal detectable effect was induced by $12.5 \mathrm{nM}$ benzopyrene-7,8-diol-9,10-epoxide. In our sample, the number of $\mathrm{MN}$ was significantly higher in the 41 cord blood samples from mothers who smoked during pregnancy [smokers: 4 (1; 10.5); nonsmokers: $3(0 ; 8) ; p=0.016]$. Therefore, the data reported herein support the hypothesis that tobacco compounds are able to induce chromosomal losses and breaks that are detectable as an increased number of micronuclei. (Pediatr Res 60: 180-184, 2006)
\end{abstract}

$\mathrm{T}$ obacco carcinogenicity is dependent on the activation of solid phase neutral compounds in the smoke by organic enzymes (CYP1A1, GST). Once activated, these compounds are able to induce molecular alterations (mutation in target genes) and cellular alterations (chromosomal aberrations and micronuclei induction). The activated molecule capable of causing most genetic damage is BPDE, which is able to establish covalent bonds with DNA and derives from benzopyrene (BP, neutral-solid phase) after a series of biotransformations mediated by the P450 enzymatic system $(1,2)$.

Tobacco consumption among women is an important problem, given the increasing rate and effects on fertility and gestation (3); it is estimated that $12-20 \%$ of women smoke during pregnancy (4), although the exact rate is difficult to establish because many pregnant women deny being smokers in their first clinical consultation. Certain tobacco compounds

Received November 30, 2005; accepted March 16, 2006.

Correspondence: Ana Patiño García, Ph.D., Laboratory of Pediatrics, Los Castaños Building, University of Navarra, 31080 Pamplona, Spain; e-mail: apatigar@unav.es

Partial financial support for this research project was provided by "Fundación Echébano."

DOI: $10.1203 / 01 . p d r .0000228327 .63820 .41$ can cross the placental barrier and induce alterations in fetal development and growth (5). The presence of tobacco-specific metabolites has been detected in the fetal fluids and urine of fetuses and newborns, which strongly suggests a genotoxic effect of tobacco smoke upon newborns from mothers who smoke during pregnancy $(6,7)$. Although different studies have demonstrated the presence of chromosomal aberrations, sister chromatid exchanges and/or increased number of micronuclei in peripheral blood from smokers, which reflect different types of genetic instability, the effect of the genotoxic agents on the fetus is poorly documented. Recently, de la Chica and coworkers (8) have demonstrated that smoking 10 cigarettes or more during pregnancy significantly increases chromosomal instability in amniocytes represented by an increased number of gaps, breaks, and structural chromosomal aberrations. What is more, they detected that the chromosomal region most affected by tobacco smoke was 11q23, a region frequently altered in different neoplasias of hematologic origin.

$\mathrm{MN}$ are cytoplasmic bodies of nuclear origin corresponding to genetic material such as whole chromosomes or chromosome fragments, which, during cell division, have not been incorporated in the main nuclei of daughter cells. The unincorporated chromosomal material is the result of chromosome breaks and/or errors during the replication and division of DNA and reflect the underlying genetic instability (9). The use of $\mathrm{MN}$ as a method to estimate genetic instability was improved with the development of the cytokinesis-block micronucleus (CBMN) assay, which allows MN to be scored specifically in cells that have completed only one nuclear division. The CBMN assay has since been validated by an international and multicentric committee (HUMN) (10) and is one of the most commonly used methods for evaluating the effects of potential mutagens on human lymphocytes.

Some of the studies on MN frequency in human populations found that cigarette smoke did not affect $\mathrm{MN}$ frequency (11-13), whereas many others (14-16) found that smoking and increased $\mathrm{MN}$ index were positively correlated. These

Abbreviations: BPDE, benzopyrene-7,8-diol-9,10-epoxide; cyt-B, cytochalasin-B; HUMN, Human MicroNucleus project; MN, micronucleus/micronuclei; THF, tetrahydrofuran 
different results may be due to differences in definitions of the eligibility criteria of the smoking group. Two recent publications $(17,18)$ detected a significant increase in MN frequency in individuals smoking more than 20 cigarettes per day.

The aims of the study reported here were to establish and validate a MN assay protocol applicable to cord blood samples and then to use this assay to assess the genotoxic effect of tobacco derivatives on the fetal blood of newborns whose mothers smoked during pregnancy.

\section{METHODS}

Patients and samples. Fetal blood samples with CPDA-1 as anticoagulant (CPDA, citrate, sodium phosphate, dextrose and adenine; Terumo Medical Corporation, Somerset, NJ) were obtained from the cord blood of 143 newborns (102 from mothers who never smoked and 41 from mothers who were smoking more than 10 cigarettes per day during pregnancy).

The study was approved by the Human Ethics Committee of the University Clinic and Virgen del Camino Hospital in Pamplona, Spain. All participants were informed about the protocol and written informed consent was obtained.

Only samples from pregnancies without complications and that concluded in spontaneous births at term (37-42 wk) were included. The samples came from a randomly chosen consecutive series of women who fulfilled the inclusion criteria described above and who were matched for age. In all cases, both the mother and father completed a questionnaire covering their medical history, exposure to chemicals, and passive and active tobacco smoke exposure at home and at work. For a subset of randomly selected cases and for all in which mother and father gave contradictory answers in their questionnaires $(n=10)$, the cotinine levels, the main metabolite of nicotine, were determined in maternal urine by gas chromatography-mass spectrometry, which has a sensitivity of $20 \mathrm{ng} / \mathrm{mL}$ (Reference Laboratory, Barcelona, Spain) (19).

MN assay. Fresh blood was diluted 1:1 with Hank's solution (Invitrogen, Carlsbad, CA) and lymphocytes were isolated by red blood cells sedimentation by Lymphoprep gradient (Nycomed, Roskilde, Denmark). Cell concentration was measured using a hemocytometer and 500,000 viable cells (determined by trypan blue staining) were cultured in RPMI 1640 medium (Invitrogen) containing 10\% FCS (Invitrogen) and 1\% penicillin/streptomycin (Invitrogen). Lymphocytes were then stimulated by adding phytohemagglutinin (PHA-P, Sigma Chemical Co., St. Louis, MO) and incubated at $37^{\circ} \mathrm{C} / 5 \%$ $\mathrm{CO}_{2}$. Forty-four hours after PHA stimulation cyt-B (Sigma Chemical Co.) was added to block cytokinesis. Twenty-eight hours after cyt-B addition, cells were harvested by centrifugation, hypotonically treated with $0.075 \mathrm{M} 4^{\circ} \mathrm{C}$ $\mathrm{KCl}$, and fixed with methanol:acetic acid (24:1 ratio) for $30 \mathrm{~min}$ at room temperature. Lymphocytes, in fresh fixative, were dropped into clean, iced slides, air-dried and stained with $10 \%$ Giemsa for 5-10 min at pH 7 (20).

MN count was performed on an average of 2000 binucleated lymphocytes (1000 binucleated cells per slide) with preserved cytoplasms (duplicate cultures per sample) following the criteria established by the HUMN for MN and apoptotic cells (21). The MN assay was performed blind with respect to maternal smoking status.

Testing the MN assay with BPDE. Over $4 \mathrm{wk}$, the lymphocytes from the cord blood from a further four healthy, nonsmoking mothers were also isolated as described above. These women were not included in the control nonsmoking control group and their samples were only used for the purposes of validation of the assay.

After $39 \mathrm{~h}$ of culture, a range of concentrations of BPDE (with THF as co-solvent) (Midwest Research Institute, Kansas City, MO) was added for a period of $5 \mathrm{~h}$. Cells were then washed with PBS to remove nonincorporated BPDE, cyt-B was added, and the protocol was continued as described above.

Statistical analysis. In the design of the internal validation of the MN assay, one-way ANOVA was used to test if the mean number of MN increased with BPDE dose. The Dunnett multiple contrast test was used to evaluate differences among pairs of MN means at different BPDE doses.

The nonparametric Kruskal-Wallis test was used to test whether the number of apoptotic cells varied with BPDE dose and the Mann-Whitney $a$ posteriori test was used to evaluate differences among means of apoptotic cells at different BPDE doses.

Also, the nonparametric Kruskal-Wallis test was used to evaluate differences in the median number of MN in the smoking and nonsmoking groups.

For descriptive purposes, the parametric variables are expressed as mean (SD) whereas the nonparametric are expressed as median (interquartile range).
In all cases, $p$ values were considered significant at $p<0.05$ and the statistical analyses were carried out with SPSS version 11.0 (SPSS, Chicago, IL).

\section{RESULTS}

The MN assay is a delicate technique that requires manipulation of cultured cells submitted to a lengthy protocol (4 d). Our approach was to set-up the standard protocol described by the HUMN project and then modify it for application to cord blood cells.

The cyt-B concentration range recommended in the literature is $3-6 \mu \mathrm{g} / \mathrm{mL}$. These concentrations either yielded very few binucleated cells $(3 \mu \mathrm{g} / \mathrm{mL})$ or induced a cytotoxic effect on viability $(6 \mu \mathrm{g} / \mathrm{mL})$ so that we settled for a cyt-B concentration of $4.5 \mu \mathrm{g} / \mathrm{mL}$, which was optimal for culture conditions and yielded $35-60 \%$ of binucleated cells in 500 viable cells (22) (Fig. 1).

For the final fixative stage, methanol:acetic acid in the ratio of 24:1 was used, which yielded an optimal staining of cells and nuclei while preserving nuclear and cytoplasm membrane integrity. Other ratios such as 23:2 were tried, but these resulted in paler cytoplasmic staining, which complicated MN scoring.

An internal validation of the MN assay was then designed with the intention of determining the minimal dose of BPDE that significantly increases the MN index. We initially tried BPDE in concentrations $4,2,1$, and $0.4 \mu \mathrm{M}$ as indicated by the available literature $(23,24)$. These concentrations turned out to be cytotoxic for cultured lymphocytes. We then proceeded with BPDE concentrations increasing from $3.125 \mathrm{nM}$ to $0.2 \mu \mathrm{M}$ (Table 1). $\mathrm{MN}$ and apoptotic cells were scored at seven different BPDE concentrations (doses 1-7), without BPDE (dose 0), and with THF alone. The test was done four times over 4 consecutive weeks.

The mean number of MN increased with BPDE dose in a statistically significant manner $(p<0.0001$, ANOVA) and the Dunnett a posteriori test showed that the minimal detectable effect was induced by dose 3 , which corresponded to $12.5 \mathrm{nM}$ BPDE $(p=0.003)$. No significant differences in the MN scores were detected at doses higher than $12.5 \mathrm{nM}$ or between the THF control and doses from 0 to $6.25 \mathrm{nM}$ BPDE (Fig. 2).

The number of apoptotic cells also statistically increased with BPDE dose $(p=0.001$, Kruskal-Wallis test $)$ and the Mann-Whitney a posteriori test showed that the minimal detectable effect was induced, again, by $12.5 \mathrm{nM} \operatorname{BPDE}(p=$ 0.029) (Fig. 2).

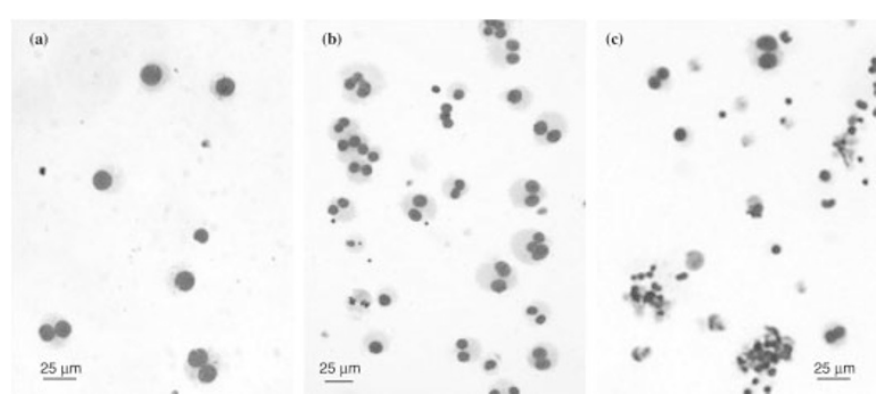

Figure 1. Cord blood lymphocyte preparations of the MN assay at 40×: (a) $3 \mu \mathrm{g} / \mathrm{mL},(b) 4.5 \mu \mathrm{g} / \mathrm{mL}$, and (c) $6 \mu \mathrm{g} / \mathrm{mL}$ of cytochalasin-B, respectively. 
Table 1. Summary of $M N$ scores and apoptotic indexes during the internal validation protocol

\begin{tabular}{lcl}
\hline \multicolumn{1}{c}{ BPDE dose } & $\begin{array}{c}\text { MN/1000 } \\
\text { binucleated cells } \\
\text { Mean }(\mathrm{SD})\end{array}$ & $\begin{array}{c}\text { Apoptotic cells/1000 } \\
\text { viable cells } \\
\text { Median* (IQR) }\end{array}$ \\
\hline Negative $(\mathrm{THF})$ & $5(1.22)$ & $60.5(51.5 ; 68.75)$ \\
Dose 0 & $4(0.71)$ & $61.5(40.5 ; 70.5)$ \\
Dose $1(3.125 \mathrm{nM})$ & $7.5(1.66)$ & $89(73.5 ; 95.5)$ \\
Dose 2 $(6.25 \mathrm{nM})$ & $8.75(1.48)$ & $108.5(72.5 ; 175.25)$ \\
Dose $3(12.5 \mathrm{nM})$ & $13.5(2.69) \dagger$ & $141.5(76.25 ; 206.75) \ddagger$ \\
Dose $4(25 \mathrm{nM})$ & $15.5(2.69)$ & $173(88.25 ; 257)$ \\
Dose $5(50 \mathrm{nM})$ & $15(3.00)$ & $235(178.75 ; 294.25)$ \\
Dose $6(0.1 \mu \mathrm{M})$ & $16(2.92)$ & $304(290.5 ; 310)$ \\
Dose $7(0.2 \mu \mathrm{M})$ & $17.25(4.21)$ & $413(385 ; 495)$ \\
\hline
\end{tabular}

The mean number of MN increased with BPDE dose and the minimal detectable effect was induced by $12.5 \mathrm{nM}$ BPDE $(p<0.0001$, ANOVA; $p=$ 0.003 ; Dunnett a posteriori test). The number of apoptotic cells also statistically increased with BPDE dose, and the minimal detectable effect was induced by $12.5 \mathrm{nM}$ BPDE $(p=0.001$, Kruskal-Wallis test; $p=0.029$, Mann-Whitney a posteriori test).

* IQR, Interquartile range.

We detected no effect of THF on MN index or apoptotic cell score, so that the BPDE co-solvent was not per se cytotoxic for our lymphocyte cultures.

After validation, the adapted MN assay was used to determine the number of $\mathrm{MN}$ in cord blood samples from 102 nonsmoking mothers and 41 who smoked 10 or more cigarettes per day during pregnancy. The median (IQR) number of $\mathrm{MN}$ in cord blood samples from the mothers who smoked was $4(1 ; 10.5)$, which was significantly higher than that of samples coming from nonsmoking pregnant women, $3(0 ; 8)$ (Kruskal-Wallis, $p=0.016$; Fig. 3).

For all cases in which mother and father gave partially contradictory answers in their questionnaires $(n=10)$, the cotinine levels in maternal urine were determined by gas chromatography-mass spectrometry, whose sensitivity is reported to be $20 \mathrm{ng} / \mathrm{mL}$. Six out of the 10 samples tested came from nonsmoking mothers and their median cotinine concentration was $20.5 \mathrm{ng} / \mathrm{mL}(20 ; 26)$. The remaining four cases were classified, on the basis of their cotinine determinations, $500 \mathrm{ng} / \mathrm{mL}(206 ; 717)$, as belonging to the smoking group.

\section{DISCUSSION}

Tobacco consumption among women is increasing and has negative effects on fertility and gestation (3). It is estimated that between 12 and $20 \%$ of women smoke during pregnancy (4), but the exact percentage is difficult to establish because many pregnant smokers deny smoking when asked by their doctor. Indeed, one of the difficulties of this study was to find pregnant women who were still smoking 10 or more cigarettes per day.

Although there are various studies which have found genetic instability (indicated by the presence of chromosomal aberrations, sister chromatid exchanges and/or an increased number of $\mathrm{MN}$ ) in the peripheral blood cells of smokers (reviewed in 25,26), the effects of tobacco-specific metabolites on the fetus are poorly documented. It is known that some compounds in tobacco smoke can cross the placental barrier and the presence of tobacco-specific metabolites has been detected in the fetal fluids and the urine of fetuses and newborns $(6,7)$. Furthermore, such compounds have been shown to induce alterations in fetal growth and development (5).

Likewise, studies that evaluate whether the frequency of $\mathrm{MN}$ increases in individuals who smoke are controversial, and both negative (11-13) and positive (14-16) correlations have been detected.

To our knowledge, there is only one study that specifically analyzes the frequency of $\mathrm{MN}$ in children (2-15 y) exposed to environmental tobacco smoke (ETS), and this study concluded that ETS-exposed children showed significantly higher MN frequencies than non-ETS-exposed children (27). In a recent meta-analysis and review of the literature, Neri and coworkers (28) reported that chromosome aberrations and MN were consistently increased in children exposed to environmental pollutants. They also conclude that in utero exposure to tobacco smoke compounds were associated with increased frequencies of DNA and $\mathrm{Hb}$ adducts and chromosomal aberrations. Their conclusions, as those reported herein, argue for a susceptibility of the fetus to tobacco smoke.

In a recent study, de la Chica and co-workers (8) detected a significant increase in the number of chromosomal gaps, breaks, and structural aberrations in amniocytes from women who smoked 10 or more cigarettes per day during pregnancy. The data reported here indicate increased $\mathrm{MN}$ in cord blood cells from such mothers $(p=0.016)$. Our results corroborate those of de la Chica and co-workers and support the hypothesis that tobacco compounds are able to induce chromosomal losses and/or breaks.

One of the main limitations in the published studies that aim to correlate the damage induced by tobacco smoke with chromatid-type chromosomal aberrations is that such aberrations are usually formed in the last round of replication before metaphase scoring and, therefore, they are formed in culture and not in the exposed individual. The MN assay detects both the chromatid and chromosome-type chromosomal aberrations and cell division is a necessary condition for MN appearance because only the acentric fragments excluded from daughter cell nuclei at telophase can produce MN (29). In some studies, the lack of correlation between results in terms of the frequencies of chromosomal aberrations and/or sister chromatid exchanges and MN (11) may be due to the fact that aberration frequencies are determined at a single point in time and are considered instantaneous mean frequencies, whereas those of MN are running means based on the cumulative number of MN derived from all divisions before the time of scoring (30).

Age is a host factor that may be involved in determining the baseline number of MN $(9,10)$. To rule out a possible effect of age on the number of MN detected, while we selected samples from a randomly chosen consecutive series of mothers, we excluded mothers at the age extremes, so that the smoking and nonsmoking groups did not differ in maternal age $(p=0.547$, data not shown). In the report by de la Chica et al. (8), the mean age of the smoking group was significantly higher than that of the nonsmoking group. Nevertheless, the authors found 

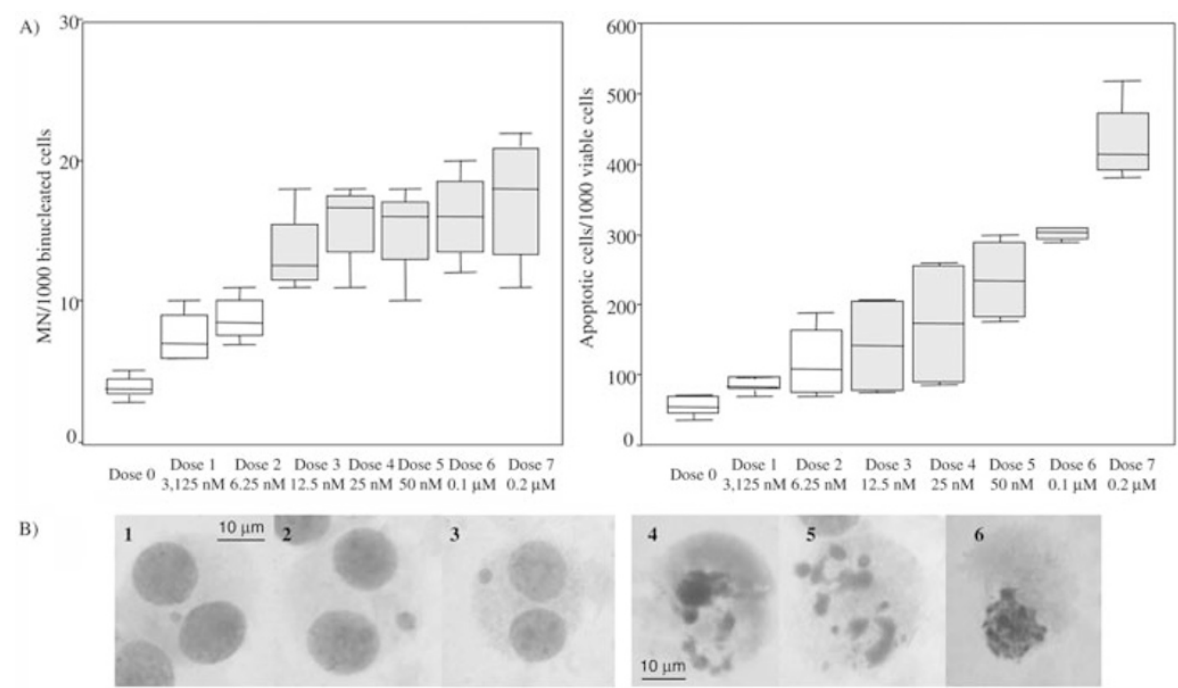

Figure 2. (A) Schematic representation of the MN index and number of apoptotic cells in the different BPDE doses tested. As indicated by the different fill color, the minimal detectable effect was induced by $12.5 \mathrm{nM} \mathrm{BPDE}$, both for MN $(p=0.003)$ and for apoptotic cells $(p=0.029)$. (B) Microscope view of BN cells with MN (1-3) and cells in different stages of apoptosis (4-6).

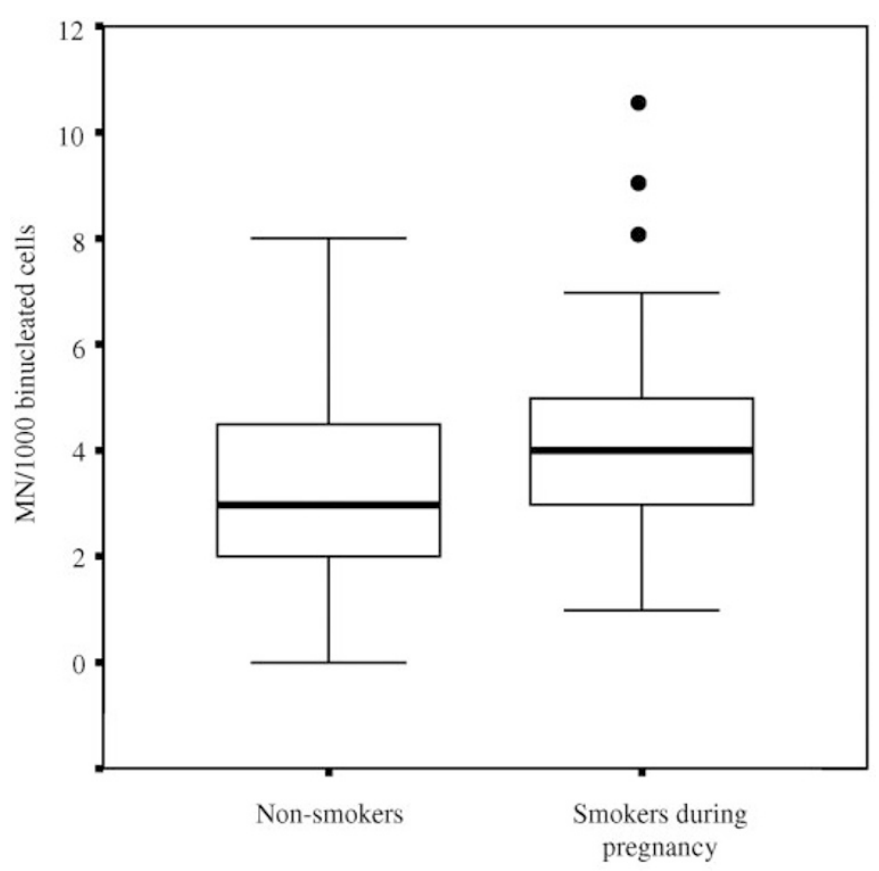

Figure 3. Comparison of the MN frequency in fetal blood samples from smoking $(n=41)$ and nonsmoking mothers $(n=102)$. The values are expressed as median and interquartile range, and outliers are marked as circles. The median number of MN in cord blood samples from the mothers who smoked was $4(1 ; 10.5)$, which was significantly higher than that of nonsmoking pregnant women, $3(0 ; 8)$ (Kruskal-Wallis, $p=0.016$ ).

that the increase in chromosomal aberrations was statistically significant whether maternal age was included as a covariate or not.

In our study, the overall average MN frequency was 3.5 (data not shown) which is in good agreement with previous studies that analyze the frequency of $\mathrm{MN}$ in healthy children (11). It is also interesting to observe that the mean $\mathrm{MN}$ frequency was not significantly different for male and female newborns $(p=0.909)$ and neither was it significantly different for mothers over $35 \mathrm{y}$ old at time of giving birth $(p=0.203)$.
In a recent review of the $\mathrm{MN}$ frequency in children exposed to environmental mutagens, it was concluded that the consistency of the results from the different studies argues against any clear effect of gender on MN frequency $(31,32)$.

The MN assay is an alternative to the conventional test for chromosomal aberrations, which analyzes the alterations present in metaphase preparations. In this sense, the MN assay is useful to detect both structural (clastogenic effect) and numerical chromosomal aberrations (aneugenic effect). Other advantages of the technique are its sensitivity (given that MN are scored in cells that have completed a nuclear division), increased power of statistical testing when scoring thousands instead of hundreds of cells, and the reduced costs of the assay (33). Our results, although preliminary, support the hypothesis that smoking during pregnancy increases the genetic instability of the fetus, and that the MN assay is a valid tool to detect such an instability.

Acknowledgments. The authors thank Dra. Adela Lopez de Cerain and the Department of Toxicology of the University of Navarra for their assistance with the MN assay and David Burdon for his reading of the manuscript. We also thank all blood donors for their cooperation.

\section{REFERENCES}

1. Hussain SP, Amstad P, Raja K, Sawyer M, Hofseth L, Shields PG, Hewer A, Phillips DH, Ryberg D, Haugen A, Harris CC 2001 Mutability of p53 hotspot codons to benzo (a) pyrene diol epoxide (BPDE) and the frequency of p53 mutations in nontumorous human lung. Cancer Res 61:6350-6355

2. Matter B, Wang G, Jones R, Tretyakova N 2004 Formation of diastereomeric benzo[a]pyrene diol epoxide-guanine adducts in $\mathrm{p} 53$ gene-derived DNA sequences. Chem Res Toxicol 17:731-741

3. Seltzer V 2003 Smoking as a risk in the health of women. Int J Gynaecol Obstet 82:393-397

4. Cnattingius S 2004 The epidemiology of smoking during pregnancy: smoking prevalence, maternal characteristics, and pregnancy outcomes. Nicotine Tob Res 6:S125-S140

5. Shankaran S, Das A, Bauer CR, Bada HS, Lester B, Wright LL, Smeriglio V 2004 Association between patterns of maternal substance use and infant birth weight, length, and head circumference. Pediatrics 114:e226-e234

6. Lackmann GM, Salzberger U, Tollner U, Chen M, Carmella SG, Hecht SS 1999 Metabolites of a tobacco-specific carcinogen in urine from newborns. J Natl Cancer Inst 91:459-465 
7. Jauniaux E, Gulbis B, Acharya G, Thiry P, Rodeck C 1999 Maternal tobacco exposure and cotinine levels in fetal fluids in the first half of pregnancy. Obstet Gynecol 93:25-29

8. de la Chica RA, Ribas I, Giraldo J, Egozcue J, Fuster C 2005 Chromosomal instability in amniocytes from fetuses of mothers who smoke. JAMA 293:1212-1222

9. Fenech M, Holland N, Chang WP, Zeiger E, Bonassi S 1999 The HUman MicroNucleus Project-An international collaborative study on the use of the micronucleus technique for measuring DNA damage in humans. Mutat Res 428:271-283

10. Bonassi S, Fenech M, Lando C, Lin YP, Ceppi M, Chang WP, Holland N, Kirsch-Volders M, Zeiger E, Ban S, Barale R, Bigatti MP, Bolognesi C, Jia C, Di Giorgio M, Ferguson LR, Fucic A, Lima OG, Hrelia P, Krishnaja AP, Lee TK, Migliore L, Mikhalevich L, Mirkova E, Mosesso P, Muller WU, Odagiri Y, Scarffi MR, Szabova E, Vorobtsova I, Vral A, Zijno A 2001 HUman MicroNucleus project: international database comparison for results with the cytokinesis-block micronucleus assay in human lymphocytes: I. Effect of laboratory protocol, scoring criteria, and host factors on the frequency of micronuclei. Environ Mol Mutagen 37:31-45

11. Barale R, Chelotti L, Davini T, Del Ry S, Andreassi MG, Ballardin M, Bulleri M, He J, Baldacci S, Di Pede F, Gemignani F, Landi S 1998 Sister chromatid exchange and micronucleus frequency in human lymphocytes of 1,650 subjects in an Italian population: contribution of sex, age, and lifestyle. Environ Mol Mutagen 31:228242

12. Bukvic N, Gentile M, Susca F, Fanelli M, Serio G, Buonadonna L, Capurso A, Guanti G 2001 Sex chromosome loss, micronuclei, sister chromatid exchange and aging: a study including 16 centenarians. Mutat Res 498:159-167

13. Bolognesi C, Perrone E, Landini E 2002 Micronucleus monitoring of a floriculturist population from western Liguria, Italy. Mutagenesis 17:391-397

14. Au WW, Walker DM, Ward JB Jr, Whorton E, Legator MS, Singh V 1991 Factors contributing to chromosome damage in lymphocytes of cigarette smokers. Mutat Res 260:137-144

15. Tomanin R, Ballarin C, Nardini B, Mastrangelo G, Sarto F 1991 Influence of smoking habit on the frequency of micronuclei in human lymphocytes by the cytokinesis block method. Mutagenesis 6:123-126

16. Di Giorgio C, De Meo MP, Laget M, Guiraud H, Botta A, Dumenil G 1994 The micronucleus assay in human lymphocytes: screening for inter-individual variability and application to biomonitoring. Carcinogenesis 15:313-317

17. Bonassi S, Neri M, Lando C, Ceppi M, Lin YP, Chang WP, Holland N, KirschVolders M, Zeiger E, Fenech M 2003 Effect of smoking habit on the frequency of micronuclei in human lymphocytes: results from the Human MicroNucleus project. HUMN collaborative group. Mutat Res 543:155-166

18. Wu PA, Loh CH, Hsieh LL, Liu TY, Chen CJ, Liou SH 2004 Clastogenic effect for cigarette smoking but not areca quid chewing as measured by micronuclei in exfoliated buccal mucosal cells. Mutat Res 562:27-38

19. Ji AJ, Lawson GM, Anderson R, Dale LC, Croghan IT, Hurt RD 1999 A new gas chromatography-mass spectrometry method for simultaneous determination of total and free trans- $3^{\prime}$-hydroxycotinine and cotinine in the urine of subjects receiving transdermal nicotine. Clin Chem 45:85-91

20. Fenech M 1993 The cytokinesis-block micronucleus technique: a detailed description of the method and its application to genotoxicity studies in human populations. Mutat Res 285:35-44

21. Fenech M, Chang WP, Kirsch-Volders M, Holland N, Bonassi S, Zeiger E 2003 HUman MicronNucleus project. HUMN project: detailed description of the scoring criteria for the cytokinesis-block micronucleus assay using isolated human lymphocyte cultures. Mutat Res 534:65-75

22. Fenech M 2000 The in vitro micronucleus technique. Mutat Res 455:81-95

23. Li D, Firozi PF, Wang LE, Bosken CH, Spitz MR, Hong WK, Wei Q 2001 Sensitivity to DNA damage induced by benzo (a) pyrene diol epoxide and risk of lung cancer: a case-control analysis. Cancer Res 61:1445-1450

24. Xiong P, Bondy ML, Li D, Shen H, Wang LE, Singletary SE, Spitz MR, Wei Q 2001 Sensitivity to benzo(a)pyrene diol-epoxide associated with risk of breast cancer in young women and modulation by glutathione S-transferase polymorphisms: a casecontrol study. Cancer Res 61:8465-8469

25. DeMarini DM 2004 Genotoxicity of tobacco smoke and tobacco smoke condensate: a review. Mutat Res 567:447-474

26. Husgafvel-Pursiainen K 2004 Genotoxicity of environmental tobacco smoke: a review. Mutat Res 567:427-445

27. Baier G, Stopper H, Kopp C, Winkler U, Zwirner-Baier I 2002 Respiratory diseases and genotoxicity in tobacco smoke exposed children. Laryngorhinootologie 81:217225

28. Neri M, Ugolini D, Bonassi S, Fucic A, Holland N, Knudsen LE, Sram RJ, Ceppi M, Bocchini V, Merlo DF 2006 Children's exposure to environmental pollutants and biomarkers of genetic damage. II. Results of a comprehensive literature search and meta-analysis. Mutat Res 612:14-39

29. Savage JR 2000 Micronuclei: pitfalls and problems. Atlas Genet Cytogenet Oncol Haematol. Available at: http://www.infobiogen.fr/services/chromcancer/Deep/ MicronucleiID20016.html (accessed May 24, 2005)

30. Demarini DM, Preston RJ 2005 Smoking while pregnant: transplacental mutagenesis of the fetus by tobacco smoke. JAMA 293:1264-1265

31. Neri M, Ceppi M, Knudsen LE, Merlo DF, Barale R, Puntoni R, Bonassi S 2005 Baseline micronuclei frequency in children: estimates from meta- and pooled analyses. Environ Health Perspect 113:1226-1229

32. Levario-Carrillo M, Sordo M, Rocha F, Gonzalez-Horta C, Amato D, OstroskyWegman P 2005 Micronucleus frequency in human umbilical cord lymphocytes. Mutat Res 586:68-75

33. Marzin D 1997 The position of the in vitro micronucleus test within the battery of screening for genotoxic potential determination and the regulatory guidelines. Mutat Res 392:175-181 